\title{
Action and the representation of distance in cognitive maps acquired through imagined traversal: The development of a new methodology
}

\author{
DaVi Bugmann \\ University of Plymouth, Plymouth, England \\ AND \\ KenNy R. COVENTRY \\ Northumbria University, Newcastle Upon Tyne, England \\ and Hanse Institute for Advanced Studies, Delmenhorst, Germany
}

\begin{abstract}
A new methodology examined the effects of action on memory for traversed distance using an imagined route traversal task. Blindfolded participants learned environments through auditory verbal description, imagining themselves walking in synchronization with metronome beats. Participants were turned during traversals, and performed an action at midroute. Memory for the newly learned environments was tested through recall (measured with metronome beats). Experiments 1-3 indicated that the number (but not amplitude) of turns while imagining walking a set distance leads to an increase in perceived distance at recall. Additionally, Experiment 2 found that rewalked distance immediately prior to performing an action at midroute was greater than rewalked distance immediately after action. However, Experiment 3 established that the effect was due to time spent at midroute rather than action per se. The similarity between spatial representation derived from imagined traversal and real traversal, and the relationship between distance and time estimation are discussed.
\end{abstract}

Navigating around one's environment involves constructing mental representations, or cognitive maps, of the world (e.g., Downs \& Stea, 1977; Tolman, 1948). Cognitive maps contain spatial information comprising the existence of elements (objects and places), the directional relationships among the elements, and the distance separating the elements. However, when asked how far it is from one place to another, people, as evidence shows, produce systematic errors in distance estimations; cognitive distance is systematically distorted from physical distance (Golledge, 1987, 1999).

As well as constructing cognitive maps through direct experience of the spatial world, spatial representations can also be formed more indirectly through a variety of media, including diagrams (e.g., Bryant \& Tversky, 1999; Rinck \& Denis, 2004), maps (e.g., Richardson, Montello, \& Hegarty, 1999), and language (e.g., Avraamides, 2003; Avraamides, Loomis, Klatzky, \& Golledge, 2004; Denis \& Cocude, 1989, 1997; Taylor \& Tversky, 1992). The issue of whether such spatial representations are equivalent to those constructed through direct experience with space has begun to receive much attention (e.g., Avraamides et al., 2004; Denis \& Zimmer, 1992; Rinck \& Denis, 2004; Zwaan \& Radvansky, 1998).

The goals of this study are threefold. First, we examine whether errors in distance estimation that have been found for memory for direct route traversal are also found for memory for routes acquired indirectly in an imagery task with spatial language input. In particular, we focus on whether turning during imagined route traversal and performing actions during imagined route traversal affect imagined rewalked distance for these routes. Second, we present a new methodology as a means of examining a range of research questions in spatial cognition research that are difficult to address using currently available methodologies, while opening up the possibility of testing a range of variables in a controlled fashion. Third, we consider explanations for distance distortion effects for both directly and indirectly experienced routes, offering what we will argue is a unified explanation of a range of distance distortion effects in the literature. We explore the role that action and other events play in triggering what we will term attentional shifts as a means of accounting for a range of effects on memory for distance (and time) acquired both directly and indirectly in a parsimonious way.

The structure of the paper is as follows: First, we overview research, showing that a range of factors affect memory for distances following direct perceptual acquisition of routes; and then we consider explanations for these effects. The literature suggesting the equivalence of routes learned through direct versus indirect perception is considered. We then present the new methodology for exam-

K. R. Coventry, kenny.coventry@northumbria.ac.uk 
ining cognitive maps acquired through verbal instruction, together with the results of three experiments that support the attentional-shift explanation for distortion effects.

\section{Turns and Distance Estimation for Routes Acquired Directly}

A number of studies have examined the effects of turning during route navigation. Sadalla and Magel (1980) asked participants to walk paths, laid out with masking tape on the hallway floors of a psychology building, that contained two or seven turns. Immediately after completing the task, participants were asked to give distance estimations, using ratio estimation, and to draw the paths just walked. The number of turns contained in each path influenced the perception of path length. Paths with seven turns were estimated and drawn as being longer than those with two turns.

Prominent among theories explaining the influence of turns on distance estimation is the scaling hypothesis (Sadalla \& Magel, 1980), which maintains that a rightangle turn divides a pathway into segments and that the perceived lengths of the segments are combined to produce an estimate of the total pathway length. Given the general tendency to overestimate short distances and underestimate long ones, longer segments will be more compressed than shorter segments. Therefore, the combination of a number of compressed segments will yield a relatively underestimated total pathway length; this underestimation is greater for pathways with fewer turns than for pathways of equivalent length with more turns.

However, several more recent studies suggest that the "number-of-turns" effect may be due to the fact that Sadalla and Magel (1980) used a relatively homogenous (nondifferentiated, nonsegmented) environment. Herman, Norton, and Klein (1986) asked participants to walk along paths between two locations separated by different numbers of turns, and then to estimate walking distances by walking along a straight corridor and stopping when they had walked an equivalent distance. The results showed no evidence for the effect of number of turns; straight paths and cornered paths did not influence participants' distance estimation (although they remembered the number of turns in each path).

Herman et al. (1986) suggest that the disparity between their results and the results of Sadalla and Magel (1980) may be attributed to differences in the number and complexity of visual cues in the environment. While Sadalla and Magel used a taped path on a single hallway floor, in Herman et al.'s study the visual environment was much richer, because they used more naturalistic environments (e.g., open-plan school recreation rooms and school corridors). Thus, it would appear that visual information potentially confounds any attempt to assess the effect of action on memory for traversed distance.

A second factor that affects how one remembers distance is the relationship between visual flow, distance traversed, speed of travel, and degree of biomechanical effort. Rieser, Pick, Ashmead, and Garing (1995) asked participants to walk on a treadmill pulled by a tractor which allowed the relative rates of biomechanical activity and environmental (visual) flow to be changed artificially. They then compared participants' accuracy of walking blindfolded in a straight line to a target pre- and posttreadmill. In the fast condition, the treadmill operated at $8 \mathrm{kph}$ and the trailer at $5 \mathrm{kph}$. In the slow condition, the treadmill operated at $7 \mathrm{kph}$ and the trailer at $17 \mathrm{kph}$. The most interesting result was that after the faster condition participants walked too far, and after the slower condition, not far enough. Analysis of the gaits showed that after the faster condition participants significantly increased the number of steps walked from the pretests to the posttests, but after the slower condition, no difference in the numbers of steps walked from the pretests to the posttests was found.

There is evidence, therefore, that turning does affect memory for distance, but complexity of the visual environment and rate of biomechanical effort involved also do. We next review evidence that suggests spatial information acquired indirectly may be similar to that acquired directly, prior to presenting a new methodology that allowed us to measure whether number of turns and action exert an effect on distance estimation during navigation acquired through indirect means.

\section{Spatial Representations Acquired Through Indirect Means}

There is mounting evidence that spatial representations acquired indirectly share properties with spatial representations constructed through direct perception. A number of studies have shown that the properties of physical layouts are preserved when the layouts are constructed through textual description (see Zwaan \& Radvansky, 1998, for a review). For example, Denis and Cocude (1989) found that, whether or not participants learned a layout of an island through verbal description or studying a map, latencies to complete mental scans between two objects in the layout varied as a function of interobject distance (see also Kosslyn, Reiser, Farah, \& Fliegel, 1983).

It is also the case that imagining walking around a learned environment shares properties with actual traversal around that environment. Rinck and Denis (2004) instructed participants to learn the layout of buildings (presented in diagrammatic form). They then received mental imagery instructions telling them to imagine walking through the building from one room to another. Critically, the Euclidean distance between points in the layout (long vs. short distances), as well as categorical distance (a set distance divided in a single room or divided into two rooms), affected time taken to imagine motion and response times (RTs) to test probes. These results are consistent with work showing categorical effects from layouts learned directly (e.g., McNamara, 1986) and work showing Euclidean distance effects on memory for distance (e.g., Taylor \& Naylor, 2002).

The role of action, and of turning in particular, has received much attention in the direct acquisition of spatial information literature. A number of studies have shown that people update spatial relations more efficiently when they physically rotate than when they imagine themselves 
rotating (Rieser, 1989). Similarly, Avraamides (2003, Experiment 3) examined egocentric updating of spatial scenes that were encoded linguistically, rather than perceived directly, and found that egocentric relations were updated when participants physically turned but not when they imagined themselves turning. However, there is little work that has examined whether distance estimation after imagining walking is affected by similar variables as distance estimation after real walking.

In the present studies, we manipulated the influence of turns on traversed distances to assess whether there is an effect of number of turns on memory for distance under imagined (and controlled) conditions, and to get more precisely at the mental mechanisms that mediate why complex routes (with many turns) were estimated differently from less complex ones (with fewer turns) in some past studies. If effects of turning were to be found under such circumstances, we could be sure that the effects result from the action manipulation and not from a change in amount or complexity of visual information accrued during a turn. Furthermore, this would provide the first evidence that turning while imagining oneself walking exerts the same effects on distance estimation as actual walking.

Additionally, we were interested in manipulating action not just in terms of the number of turns performed during traversal, but also in the form of the completion of an action goal halfway through the route. Participants had the task of carrying an item (e.g., a parcel) and delivering it at the midpoint of the route. We thought this might be associated with an increase in distance estimations, pre- versus postdelivery, for several reasons. First, performing actions on the spot associated with movement (bending, turning) might lead participants to misremember the actions as being connected with previous actions while walking, and as a continuation of the turning actions performed on the previous path(s). The actions performed when delivering the parcel are likely to be attached to the predelivery route, given that the action is associated with the goal of delivering the parcel. Second, carrying a parcel and posting it might be associated with increased cognitive effort. Decety, Jeannerod, and Prablanc (1989) found that when participants had to imagine themselves walking to a target carrying a $25-\mathrm{kg}$ load, they thought that it would take them longer to carry the load to the target than it actually did. Similarly, memory for the task may be affected by memory of the effort of carrying a parcel in the present experiment, although walking speed was strictly controlled and the object carried was very light. Third, the delivery of the object may provide a theme to link the landmarks in the first half of the route. It has been shown that linking landmarks functionally can lead to more accurate memory for distance (S. Cohen \& Cohen, 1982). Fourth, at a more general level, the view that cognition is grounded in bodily interaction with the environment has received much recent attention (e.g., Barsalou, 1999; Glenberg, 1997), and empirical evidence supporting this claim has been found across a range of domains, including language comprehension (Glenberg \& Kaschak, 2002; Zwaan, 2004).
Hence, there are several reasons for predicting a difference in remembered distance pre- and postdelivery. If such an effect were found, it would be difficult to account for with the scaling hypothesis, and would point to a different explanation for turning effects.

\section{Development and Overview of the Methodology}

In order to test the effects of turning during indirectly acquired spatial routes, while controlling for factors such as walking speed in past studies, a new procedure was developed that eliminated all visual information during learning. Participants received information about the environment through linguistic descriptions heard over headphones while wearing a blindfold; their task was to listen and to visualize the landmarks that were described to them.

The environmental descriptions were formulated as guided tours, which were read by a female colleague and recorded for use in the experiments. Actual walking was replaced by a mental walk; a metronome preset to each participant's stride length and speed of step mirrored each participant's natural walking rhythm as the participant was guided on a mental walk through the environment. Participants were instructed that their memory for described places was being tested; we hoped that this would lead participants to focus and visualize landmark descriptions, thus avoiding the potential problem that participants might simply gauge distances by counting steps. So instead of actually walking, participants heard a certain number of metronome beats, which corresponded to the exact measure of the distance to be traversed. When the distance was mentally traversed, the metronome beats ceased. After mentally walking each route, participants had the task of rewalking the route, describing the route to the experimenter along the way, and instructing the experimenter to engage and disengage the metronome when walking. This meant that imagined rewalked distance could be compared with actual imagined distance traversed during the mental walk.

\section{Environment Descriptions and Characteristics}

The environments included five landmarks (e.g., a school; a museum; a post office; a bank; a library). Each landmark was described by specifying its physical or historical features. Examples of environmental descriptions in full can be seen in the Appendixes (Appendixes A-C for Experiments 1-3, respectively).

Following is an excerpt of a typical description of an environment used in the experiments (landmarks are in boxes; mental walks and actions are in bold):

“... You are now standing at the gate of a place called Victoria Park. Victoria Park is renowned for its formal and shrub gardens. They provide interest and beauty in all seasons. During summer, Victoria Park hosts a Folk Music Festival. I am going to get you to walk away from Victoria Park along a road called Abbey Road. Start walking: Click-Click-Click... Stop. Now you turn onto a road called Mount Street (the experimenter turns the participant to the left or 


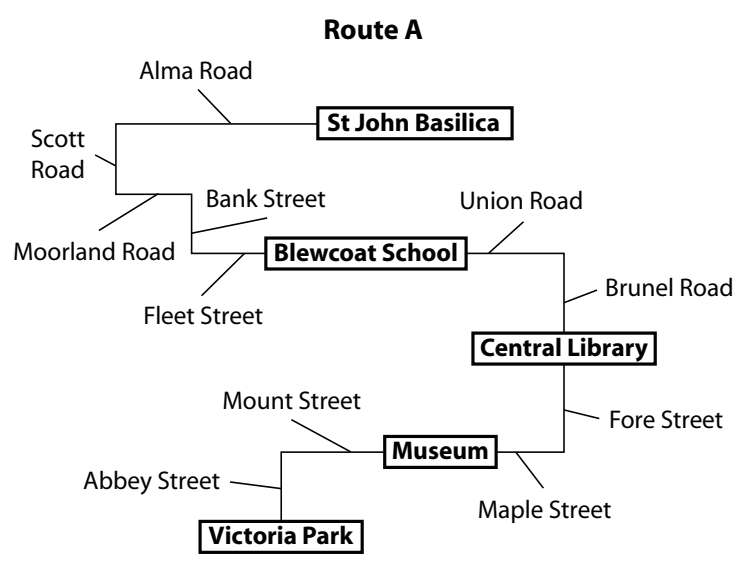

Route B

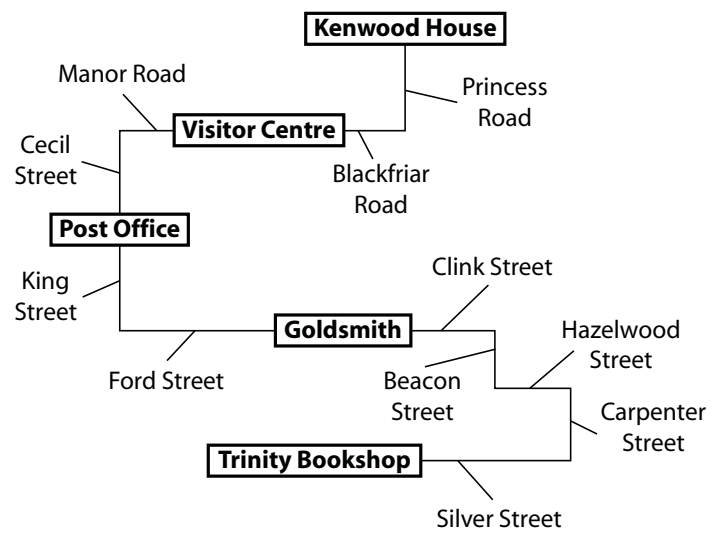

Figure 1. Schematic representation of Routes A and B used in Experiment 1 and pilot studies.

right). Start walking: Click-Click-Click... Stop ... You are now at the entrance of a place called the Central Library. Built of silvery-grey stone, the front of the building has columns and triple arches with elaborate decoration at the tops. Inside the Library, there is an intricately carved oak staircase. You are standing directly in front of the book return box. Now I will let you post the book in the return box. You can actually feel the return box in front of you. So feel the box and post the book. Now I am going to get you to walk away from the Central Library along a road called Brunel Road. Start walking: Click-ClickClick... Stop ..."

Participants learned two routes (denoted Route A and Route B in Experiment 1), unaware that Route B was Route A's mirror image (see Figure 1 for schematic representations of routes used in Experiment 1). Each route contained four paths. In Route A, a path with four turns occurred at the start of the route (the others just had a sin- gle turn), and in Route B the path with four turns occurred at the end of the route. Each path measured $64 \mathrm{~m}$ and was made up of segments with fixed lengths of $8,12,16,24$, 32 , and $40 \mathrm{~m}$. These distances were combined to make up the total route length for each route of $256 \mathrm{~m}$.

\section{Setting and Initial Setup}

The experiments were conducted in a laboratory approximately $6 \times 3 \mathrm{~m}$ in area. A box was placed on a table within arm's reach of participants. At about $50 \mathrm{~cm}$ from the table, a plus cross was marked on the floor to form a virtual circle of $60 \mathrm{~cm}$ diameter, partitioned into $15^{\circ} \mathrm{seg}$ ments (see Figure 2).

For the mental walk, we first calibrated each participant's natural walking speed with the number of beats produced by a metronome that matched the participant's exact number of steps/minute. At the start of the test, participants walked a U-shaped reference path (marked by the dotted line in Figure 2) at their own natural walking speed. The time taken to traverse the reference path was measured, as were the number of steps. These measures served to compute the speed of walks and the size of step for each participant individually [calculated as: (Number of steps to walk reference path / Time taken to walk reference path) $* 60 \mathrm{sec}$. The participant's step lengths were also calculated (the length of the reference path divided by the number of steps required to traverse it). Participants were told that each metronome beat represented one footstep forward. To convert a distance $(X)$ to be mentally traversed into the number of metronome beats, the following formula was used: (Number of steps to walk reference path / Length of reference path) $* X \mathrm{~m}$.

For the experiment, a numerical chart for several possible numbers of steps representing different distance lengths was established in advance. This chart was attached to the back of the participant for reference during the test. To ensure that participants would feel comfortable during the test, we asked them to close their eyes and to imagine walking in rhythm with the metronome beats that were preset to harmonize with their natural walking speeds. If the walking speed seemed fine for the partici-

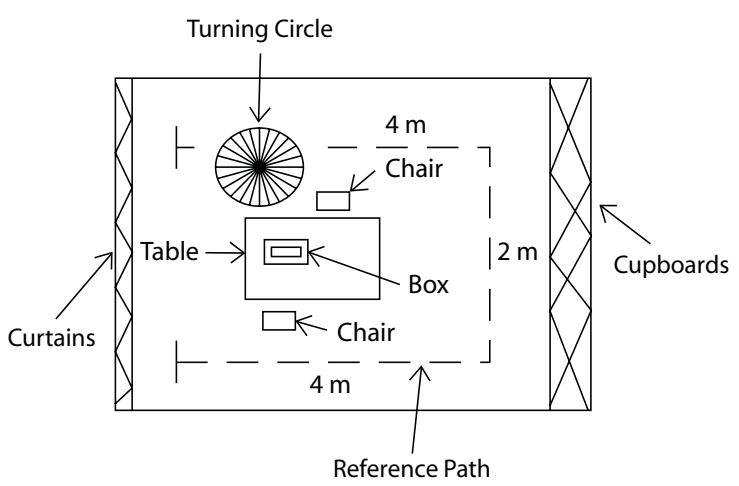

Figure 2. Room arrangement used in the experiments. 
pants, the preset speed was used during the test. Otherwise, the participant had to walk the reference path one more time in order to find the correct speed of walk.

During the test, the participants stood at the center of the marked circle (see Figure 2). They were asked to wear blindfolds and headphones. The participants also carried small backpacks containing tape recorders. The steps chart and the transcript of the route description were attached to each participant's back. These were used by the experimenter to engage and disengage the metronome for the walk simulation, and to monitor the progression through the environment. The experimenter carried a tape player in a belt bag and always stood behind the participant (see Figure 3). A Y-split joint allowed both the participant and the experimenter to hear the route description simultaneously during testing; it was disconnected during the free recall.

To familiarize participants with the sense of angular displacement at turns during the imaginary trip, before the test proper began the experimenter gently rotated the participant, once to the left and once to the right (illustrated in Figure 3). Note that all turns in Experiment 1 were $90^{\circ}$ turns. Once the participant got used to the idea of being rotated, the experimenter spun the participant one more time with an uninterrupted turn clockwise or counterclockwise, finishing by positioning the participant to face the box. This was the correct starting position, but the participant was unaware of the direction. The direction of turns was also fixed for each route, so that when "arriving" at midroute, the participant was in front of the box to perform the action.

\section{Presentation}

The experiments were presented to the participants as an investigation into people's memory for described places. They were told that they were going to be guided through an imaginary walk through new environments that were described to them, and were told to visualize the described landmarks. Additionally, they were asked to put an object into a box at some point en route. The participants were not aware that their memory for distances was being tested.

\section{Pilot Studies}

Before the experiments were run, we first checked that being rotated while wearing a blindfold was not disorienting or distressing for participants. After we were sure the methodology was comfortable and relaxing for participants, we ran a first full experiment ${ }^{1}$ identical to Experiment 1 except that the verbal instructions were only given to participants once.

\section{EXPERIMENT 1}

\section{Method}

The main aim of Experiment 1 was to establish whether a number of turns effect would be present when learning a route indirectly. We also needed to establish that the new methodology was working effectively in terms of an appropriate level of task difficulty for participants. Finally, we examined whether performing an action at midpoint would affect distance estimation before and after action.
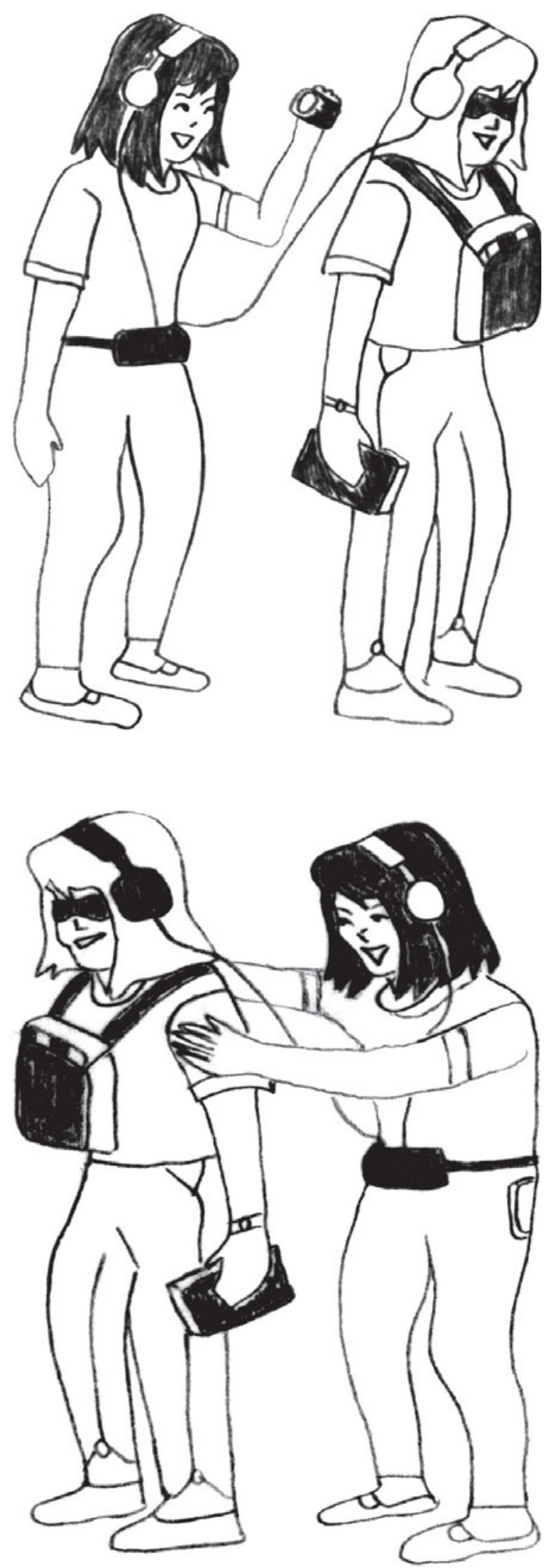

Figure 3. Arrangement during mental walking and turning procedure. 
Design. To examine the influence of action and the effect of number of turns on traversed distances, the experimental design used was a 2 route (Route A vs. Route B) $\times 2$ position (inner vs. outer) $\times$ 2 action (pre- vs. postdelivery of book/parcel) within-participants design.

Participants. Twenty-three undergraduate students, 2 men and 21 women, participated in the experiment in exchange for course credit. Participants were between 18 and 46 years old (mean age, 23.91; SD, 7.51).

Procedure. Participants were tested individually in a single session which lasted about $60 \mathrm{~min}$. Initially, they were instructed to walk a reference path at their own natural walking speed. They were told that this was done to compute their walking speeds and step lengths. Next, they were asked to put on the blindfold and headphones, and to stand comfortably at the center of the marked circle. The experimenter familiarized the participants with the turning procedure. Then the experimenter gave the participant a book or a small parcel to "carry." The participants were instructed to visualize the landmarks when they heard the descriptions, and to imagine walking in synchronization with the metronome clicks and to stop imagining walking when the metronome ceased clicking. Importantly, the experiment was presented to the participants as an investigation into people's memory for described places. They were told that they were going to be guided through an imaginary walk through new environments that were described to them, and that they had to visualize the described landmarks. Then the experimenter started the tape player and both listened simultaneously to route descriptions through headphones. At the appropriate times, the experimenter stopped the player and engaged the metronome to implement the mental walking. During turns, the experimenter physically rotated the participants on the spot so that they would face the appropriate direction. Following instructions, participants performed an action: They extended their arms to reach the box, touched it to find the slot, and then dropped the object into the box. Once the destination was reached, the experimenter spun the participant around again (uninterrupted clockwise/counterclockwise large turn) and positioned him or her in front of the box at the start of the route again, and the whole procedure was repeated. After twice being taken through the route, still blindfolded, the participant's route memory was tested through recall. After the recall of the first route, the second route was learned twice, followed straightaway by the recall.

For the recall, participants were told that they were taken back to the starting landmark and that they had to rewalk to the final destination. They were asked to describe as accurately as possible what they "saw" en route. They had to say when they wanted to walk away from the landmarks and when they wanted to stop walking, so that the experimenter could engage or disengage the metronome to simulate walks. At turns, they rotated themselves on the spot and indicated verbally the direction of turns. Once it was established that participants understood the recall procedure, the experimenter switched on the tape recorders that they carried and their descriptions and metronome clicks were recorded.

Data treatment. Once participants' protocols were transcribed, we checked that landmarks were recalled in the correct order; only responses with the correct sequence of landmarks were used in the analyses.

Data were obtained by first translating the number of metronome clicks $(=$ steps $)$ into traversed distances expressed in meters. The accuracy of turns with regard to amplitude and direction was not recorded in the present experiment.

\section{Results}

Data from 5 participants were eliminated from the analyses (four incorrect sequences of landmarks, one bad recording) leaving 18 out of 23 participants' data in the analyses ( $78 \%$ comprising 2 males and 16 females). The exposure to the environment twice seemed to be effective in reducing the rate of data exclusion, compared with the first study (see note 1).
Table 1

Mean Rewalked Distance Estimates (in Meters) With Standard Deviations in Experiment 1, by Number of Turns and Route

\begin{tabular}{cccccc}
\hline & \multicolumn{2}{c}{$\begin{array}{c}\text { Route A } \\
(1-1-1-4)\end{array}$} & & & \multicolumn{2}{c}{$\begin{array}{c}\text { Route B } \\
(4-1-1-1)\end{array}$} \\
\cline { 2 - 3 } \cline { 5 - 6 } & $M$ & & & & \\
& 45 & & & $S D$ \\
\hline 4 turns & 45.56 & 26.25 & & 44.83 & 22.57 \\
1 turn & 33.44 & 23.19 & & 28.99 & 15.33
\end{tabular}

Note-Numbers in parentheses represent the number of turns for paths as they occurred sequentially.

In order to check that participants were not just remembering the number of metronome clicks they heard and then rewalking by counting clicks, we examined whether the number of clicks, and therefore the number of steps participants walked, was associated with recalled distance. This was possible, given that the number of clicks heard for the total route distance varied across participants (because they had different step lengths). The correlations between the total number of steps to walk both Route A and rewalked distance, and between Route B and rewalked distance, were not significant $(r=-.24$ and $r=-.15$, respectively), indicating that participants were not simply remembering numbers of clicks or steps. However, the overall correlation between actual segment lengths and remembered segment distances was highly significant $[r(22)=.68, p<.001$, one-tailed], indicating that participants were sensitive at recall to length of path walked.

The mean rewalked distances (together with standard deviations) for one-turn and three-turn paths for Route $\mathrm{A}$ and Route B are displayed in Table 1. The influence of number of turns on rewalked distances was examined in a 2 (number of turns: one vs. four) $\times 2$ (routes: Route $\mathrm{A}$ vs. Route B) within-participants ANOVA. There was a significant main effect of number of turns $[F(1,17)=$ 18.767, $\left.M S_{\mathrm{e}}=187.4, p<.001\right]$. Paths with four turns were remembered/rewalked as significantly longer $(M=$ $45.19 \mathrm{~m})$ than paths with one turn $(M=31.22 \mathrm{~m})$. No other effects were significant (all $F_{\mathrm{s}}<1$ ).

To examine the possible effect of performing an action at midroute on rewalked distance, we tested whether there was a difference in rewalked distance immediately before versus after the performed action (Route A, segment 4 vs. segment 5; Route B, segment 7 vs. segment 8). For the comparisons, we used the segment ratios, which we obtained by dividing rewalked distances by their respective actual distances. A 2 (segment position: before, after action) $\times 2$ (route: Route A, Route B) within-participants ANOVA found no significant effect of segment position $\left[F(1,17)=0.41, M S_{\mathrm{e}}=0.09, p>.05\right]$. No other effects were significant (all $\left.F_{\mathrm{s}}<1\right)$.

\section{Discussion}

Exposing participants twice to the environments in order to acquire route knowledge substantially reduced the data exclusion rate observed in the pilot studies (see note 1). Although the rate of exclusion was still high $(22 \%)$, indicating that some participants' memories for routes were imprecise, the majority of participants pro- 
duced the landmarks in the correct order; therefore, their distance estimations could be analyzed.

The results are consistent with those found through direct navigation of spatial environments; paths with four turns were remembered as being longer than paths containing one turn. However, the effect of performing an action at midpoint did not affect rewalked distance before rather than after the action, either because there is no action effect, or because the action performed in this experiment was simply not salient enough. The next experiment looks more closely at the turning involved in performing actions.

\section{EXPERIMENT 2}

The failure to find an effect of action pre- versus postdelivery may be for several reasons. First, the load in Experiment 2 was much lighter than that used by Decety et al. (1989), so the cognitive effort required of participants was lower. Second, the actions used when performing the delivery task were minimal in Experiment 1 . In Experiment 2, we increased the on-the-spot action that participants were required to perform. If an effect of distance pre- versus postdelivery were then found, we could be confident that the effect had to do with the actions performed on delivery and subsequent memory for those actions (or with the time taken to perform those actions; Experiment 3).

Assuming the importance of action in the retrieval process, Experiment 2 also examined more carefully the importance of the size of turns (amplitudes). If the scaling hypothesis is correct, the size of turn should not affect remembered distance. In contrast, if action is central to remembered distance, one might expect that increased action, just like increased number of turns, should lead to longer remembered distances. To test this assumption, we manipulated the size of turns by comparing rewalked distance between segments separated by $90^{\circ}$ turns or $270^{\circ}$ turns, which involve larger body movements. The $90^{\circ}$ and $270^{\circ}$ turns were in opposite directions, thus ensuring that participants walked the same direction. Experiment 2 also examined the physical arrangement of turns within each route by varying the paths containing several turns at the inner part versus the outer part of the route (hereafter referred to as route configuration). Experiment 2 used the same methodology as Experiment 1, with minor modifications to the descriptions used (see Appendix B).

\section{Method}

The method used was the same as in Experiment 1, except that four route descriptions were used instead of two.

Environment stimuli. Four linguistic descriptions of the environments were used (denoted Routes A, B, C, and D); these are represented schematically in Figure 4. Note that, in terms of environmental layouts, Route B and Route D are mirror images of Route A and Route C, respectively; and that, furthermore, Route B used Route C's text content and Route D used Route A's text content.

In terms of route configuration, Routes A and B started with a path with one turn, followed by a path with three turns, followed by a path with three turns, followed by a path with one turn (denoted configuration 1-3-3-1). Routes $\mathrm{C}$ and $\mathrm{D}$ started with a path with three turns, followed by a path with one turn, followed by a path with one turn, followed by a path with three turns (denoted configuration 3-1-1-3). Route A and Route C started with $90^{\circ}$ turns; after performing the action, turns were $270^{\circ}$. Route $\mathrm{B}$ and Route $\mathrm{D}$ started with $270^{\circ}$ turns and after performing the action, turns were $90^{\circ}$. Each participant learned two different routes in a single configuration (either 1-3-3-1 or 3-1-1-3) and routes were presented to the participants in counterbalanced order.

Design. The experiment used a 2 (configuration: $1-3-3-1$ vs. $3-1-1-3) \times 2$ (number of turns: one vs. three) $\times 2$ (size of turns: $90^{\circ}$ vs. $\left.270^{\circ}\right) \times 2$ (action: before vs. after) mixed design. The betweenparticipants factor was configuration, and the remaining factors were within-participants factors. Two groups of participants were used. Each participant was tested under each level of turn, amplitude, and action.

Participants. Seventy-eight undergraduate students, 13 men and 65 women, participated in the experiment in exchange for course credit. They were between 18 and 46 years old (mean age, 22.01; SD, 6.53). They were randomly assigned to conditions.

Procedure. The procedure was the same as in Experiment 1. Each participant learned two routes in each condition (1-3-3-1 or $3-1-1-3)$. The test lasted about $1 \mathrm{~h}$.

Unlike Experiment 1 and the pilot study, the action was more pronounced in the present experiment. At the start of the imaginary walk, participants carried a bag containing an object (a book or a letter) in one hand and in the other an umbrella. As they "arrived" at the critical landmark (at midroute), they listened to the description of the landmark. They were told that they were in front of the box. Listening to the instructions through headphones, they performed the following sequence of movements: bending down to deposit the umbrella on the floor, taking the book or letter out of the bag, extending one arm to reach the box, feeling the slot of the box, dropping the book or letter into the box, and bending down to pick up the umbrella.

\section{Results}

Responses from 17 ( 2 men and 15 women) participants ( $22 \%$ of the total of 78 participants) were excluded from the analyses, because they did not reproduce the landmarks in the correct sequence. Data from 61 participants (11 men and 50 women) were entered into the analyses.

Again, participants did not gauge the distance through counting the number of steps as the correlation between the total number of steps required to walk the first and second routes, and their corresponding rewalked distances across participants were not significantly correlated $(r=$ -.19 and $r=-.06$, respectively).

Since each participant learned two routes, and each route contained 12 segments, there were 96 segments in total ( 12 segments $\times 4$ routes $\times 2$ groups). Overall, there was a highly significant correlation between recalled segments and their actual distances $[r(96)=.45, p<.0001$, one-tailed]. This result indicates that if there were longer segments to traverse, participants would also remember walking longer distances.

The mean rewalked distances (together with $S D$ s) by number of turns, amplitude of turn, and configuration are displayed in Table 2. A three-way ANOVA combining 2 (configuration: $1-3-3-1$ vs. $3-1-1-3) \times 2$ (number of turns: one vs. three) $\times 2$ (size of turns: $90^{\circ}$ vs. $270^{\circ}$ ) revealed a significant effect of number of turns on remembered path distances $\left[F(1,59)=54.02, M S_{\mathrm{e}}=102.9, p<\right.$ .001 ; overall three-turn paths were remembered as being longer $(M=42.10 \mathrm{~m})$ than one-turn paths $(M=32.85 \mathrm{~m})]$. There were no significant main effects of configuration or amplitude of turn (both $F$ s $<1$ ). However, the interaction 

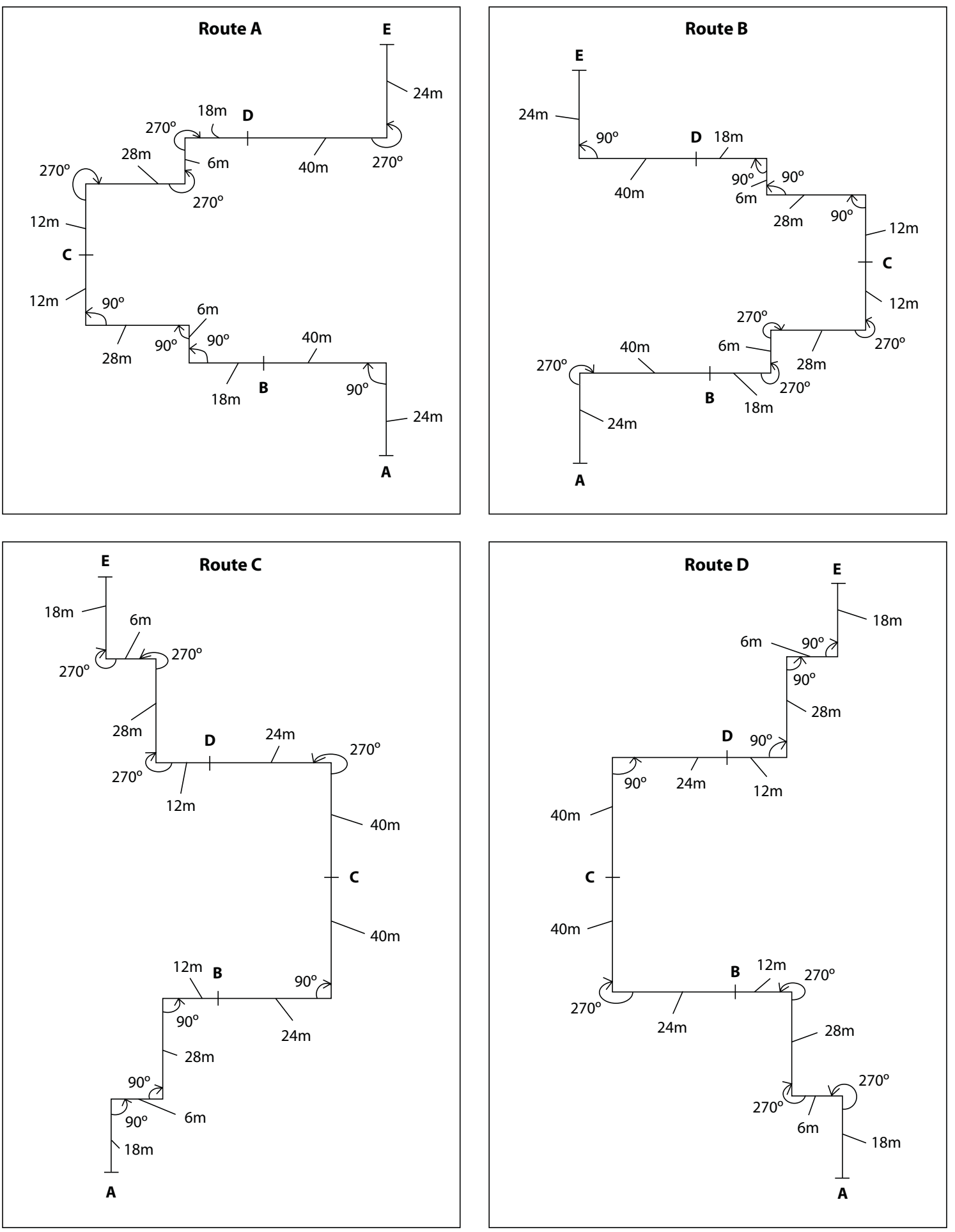

Figure 4. Schematic representation of the routes used in Experiment 2. 
Table 2

Mean Rewalked Distance Estimates (in Meters) With Standard Deviations in Experiment 2

\begin{tabular}{|c|c|c|c|c|c|c|c|c|}
\hline & \multicolumn{4}{|c|}{$\begin{array}{l}\text { Route Configuration } \\
\qquad(1-3-3-1)\end{array}$} & \multicolumn{4}{|c|}{$\begin{array}{l}\text { Route Configuration } \\
\qquad(3-1-1-3)\end{array}$} \\
\hline & \multicolumn{2}{|c|}{$270^{\circ}$ Turns } & \multicolumn{2}{|c|}{$90^{\circ}$ Turns } & \multicolumn{2}{|c|}{$270^{\circ}$ Turns } & \multicolumn{2}{|c|}{$90^{\circ}$ Turns } \\
\hline & $M$ & $S D$ & $M$ & $S D$ & $M$ & $S D$ & $M$ & $S D$ \\
\hline & 44.07 & 16.38 & 39.25 & 16.28 & 41.69 & 14.88 & 44.58 & 14.43 \\
\hline 1 turn & 33.28 & 12.58 & 34.93 & 12.88 & 30.13 & 10.21 & 33.05 & 11.99 \\
\hline
\end{tabular}

Note-Numbers in parentheses represent the number of turns for paths as they occurred sequentially.

between configuration and size of turn approached significance $\left[F(1,59)=3.51, M S_{\mathrm{z}}=87.7, p=.06\right]$. Participants in the 1-3-3-1 condition who had learned Route A and Route $\mathrm{B}$ remembered paths containing $270^{\circ}$ turns as being longer than paths containing $90^{\circ}$ turns, whereas participants in the 3-1-1-3 configuration remembered paths containing $90^{\circ}$ turns as being longer than paths containing $270^{\circ}$ turns. However, none of the pairwise comparisons were significant $(p>.05)$. None of the other interactions were significant.

We also examined whether there was a difference in rewalked distance immediately before versus after the performed action using segment ratios (following Experiment 1). A two-way ANOVA (configuration $\times$ segment position) found a significant difference immediately before $(M=0.85)$ versus immediately after $(M=0.71)$ performed action $\left[F(1,59)=5.89, M S_{\mathrm{e}}=0.04, p<.05\right]$. There was also a significant main effect of configuration $[F(1,59)=$ $\left.110.14, M S_{\mathrm{e}}=0.09, p<.0001\right]$. Distances were greater for the 1-3-3-1 group ( $M=1.14$ ) than for the 3-1-1-3 group $(M=0.46)$. The interaction between configuration and segment position was not significant $(F<1)$.

\section{Discussion}

Although the rate of exclusion was still relatively high (22\%), suggesting that some participants' memories for routes were imprecise, the majority of participants (78\%) produced the landmarks in the correct order. During the experiment, none of the participants expressed any discomfort during or after the task, indicating that the methodology was appropriate.

Consistent with the results of Experiment 1, rewalked distances were affected by the number of turns contained in a path; paths containing three turns were remembered as being longer than paths with one turn. Additionally, in this experiment - in which the action performed at midroute was more pronounced than in previous experiments - an effect of action performed midroute was observed when the segments immediately before were compared with those immediately after delivery of the book or parcel. Rewalked distances immediately prior to performing actions at the midpoint were longer than rewalked distances immediately afterward.

Overall, there was no effect of size of turn on remembered distance, the interaction between size of turn and configuration approached significance. This suggests that size of turn, if important at all for memory for distance, is only important for some configurations of route.

In summary, the results of this experiment replicate the turn effects found in Experiment 1, and provide evidence for an effect of action performed at midroute. However, the lack of an effect of degree of amplitude of turns raises some doubts regarding the role of action per se as an explanation for turning effects. Moreover, although the number-of-turns effect appears to be robust for imagined route traversal, there is an alternative explanation for the effect of action performed at midroute. Performing the extended movements of the action in this experiment necessarily involved greater time at that landmark, and therefore the difference between rewalked distance pre- versus postaction could be a function of memory for time spent at the landmark, rather than memory for action per se. Indeed, this begs the question of the relationship between distance estimation and time estimation, a much neglected issue in the spatial cognition literature, and one we return to in the General Discussion.

\section{EXPERIMENT 3}

Experiment 2 found an effect of action performed at midroute on rewalked distance. The effect was found for the segment immediately before rather than immediately after the midpoint; overall, the effect was observed when the configuration of the route had three turns in the inner paths and one turn in the outer paths (1-3-3-1). In this experiment, we wished to establish whether the effect has to do with time taken performing the action or with the action itself. For that reason, we introduced a no-action control condition, under which participants performed no action at the midpoint but stayed there for the same amount of time as in the action condition (see Appendix C).

A second major goal of the experiment was to try to reduce the data exclusion rate of previous experiments. In this experiment, in the hope of facilitating memory for landmark sequence - and hence potentially eradicating the high data exclusion rate - we changed the names of the landmarks so that they appeared in alphabetical sequence.

\section{Method}

The method used was the same as in Experiment 2, but this time only a single route was used (see Appendix C).

Environment stimuli. As before, the environment contained a series of five landmarks, but this time they were named in alphabetical sequence (e.g., Abbott, Belgrave, etc.). They were described in the same manner as in Experiment 2. In terms of route configuration, the route used a one turn - three turns - three turns - one turn sequence, and all turns were $90^{\circ}$ turns.

Design. The experiment used a 2 (condition: action vs. no action) $\times 2$ (number of turns: one vs. three) $\times 2$ (action: before vs. after) mixed design with repeated measures on the last two factors. Two groups of participants were used. Each participant was tested under each level of turn and action.

Participants. Forty-seven participants, 18 men and 29 women, agreed to participate in the experiment in exchange for course credit or money. They were between 18 and 51 years old (mean age, 24.82; $S D, 6.56)$. They were randomly assigned to conditions. 
Procedure. The procedure was the same as in Experiment 2. Each participant was exposed to the route twice. The test lasted about $40 \mathrm{~min}$. In the no-action condition, participants stood still in silence for $30 \mathrm{sec}$; this duration was equivalent to the time taken to perform the delivery action at the same location in the experimental condition.

\section{Results}

Responses from 2 male participants were excluded from the analyses, because they did not satisfy the criteria for data inclusion. Data from 45 participants -16 men and 29 women - were entered into the analyses.

The mean rewalked path distances (together with standard deviations) are displayed in Table 3. A 2 (condition: action vs. no action) $\times 2$ (number of turns: one vs. three) ANOVA was performed on path distances. There was a significant main effect of number of turns on remembered path distances $\left[F(1,43)=5.969, M S_{\mathrm{e}}=68.43, p<.05\right]$; overall three-turn paths $(M=33.77)$ were remembered as being longer than one-turn paths $(M=29.51)$. No other effects were significant.

We also examined whether there was a difference in rewalked segment distance immediately before versus after performing the delivery action. For the comparisons, we used the segment ratios, as in the previous experiments. A $2 \times 2$ ANOVA combining condition (action vs. no action) $\times$ segment position (pre- vs. postdelivery) found a significant main effect of segment position on segment distances $\left[F(1,43)=7.883, M S_{\mathrm{e}}=0.119, p=.007\right]$. Overall, participants overestimated the segment distances; however, preaction segment distances were remembered as being longer (ratio distance $=1.264$ ) than postaction segment distances (ratio distance $=1.066$ ). The main effect of condition was not significant $[F(1,43)=1.25$, $\left.M S_{\mathrm{e}}=0.207, p>.05\right]$; neither was the two-way interaction between segment position and condition $[F(1,43)=$ $\left.1.26, M S_{\mathrm{e}}=0.224, p>.05\right]$.

\section{Discussion}

The rate of exclusion dropped dramatically from $22 \%$ in Experiments 1 and 2 to $4 \%$ in the present experiment, suggesting that the strategy we used by naming landmarks alphabetically was successful. Consistent with the results of Experiments 1 and 2, imagined rewalked distances were again affected by the number of turns in a path; paths containing three turns were remembered as being longer than paths with one turn. This confirms that turning effects are robust, whether they occur in the outer or inner parts of a route.

The effect of performing a delivery action at midroute made the rewalked distance for the segment immediately

Table 3

Mean Rewalked Distance Estimates (in Meters) With Standard Deviations in Experiment 3, by Condition

\begin{tabular}{|c|c|c|c|c|}
\hline & \multicolumn{2}{|c|}{$\begin{array}{c}\text { Control } \\
\text { Condition } \\
(n=23) \\
\end{array}$} & \multicolumn{2}{|c|}{$\begin{array}{c}\text { Experimental } \\
\text { Condition } \\
(n=22) \\
\end{array}$} \\
\hline & $M$ & $S D$ & $M$ & $S D$ \\
\hline 3 turns & 33.47 & 14.25 & 34.07 & 15.67 \\
\hline 1 turn & 30.49 & 13.42 & 28.53 & 14.41 \\
\hline
\end{tabular}

before the delivery at midpoint longer than the rewalked distance for the segment immediately afterward; however, this result was also obtained in the no-action condition, under which participants did not perform actions but remained stationary for the same length of time. Therefore, the difference between rewalked distance pre- versus postmidpoint is attributable either to the time spent at the midpoint or to a simple path effect, by which distances are underestimated further as a route unfolds.

Given that Experiment 1 and the full pilot study (note 1) failed to find any effects of rewalked distance in the comparison for the segments immediately before rather than immediately after the action performed at midpoint, the simple path effect explanation is not tenable. Therefore, the key difference between the earlier experiments and this experiment is the length of time spent at the midpoint while performing the action, or waiting in the no-action condition. This suggests that time spent at a location is important for memory for distance immediately before that location, rather than after.

\section{GENERAL DISCUSSION}

In this article, our goals were threefold: First, we asked whether learning a route through indirect means, and imagining rewalking that route, would produce the number-ofturns effect observed for learning routes directly through walking. Second, we aimed to develop a new methodology to examine route learning through verbal instruction while controlling for visual information by eliminating it. Third, we wanted to investigate the role of action in route learning through indirect means, with the goal of potentially providing a unified explanation of a range of effects on memory for distance for routes learned indirectly or directly. We shall take each of these points in turn.

Several studies have shown that the number of turns one makes when walking a set distance is associated with increased distance estimates, compared with walking the same distance with fewer turns (e.g., Sadalla \& Magel, 1980). In the present experiments, the effects of turning when participants imagine walking a route are strikingly similar to the results obtained when acquiring spatial information directly. Moreover, it has been suggested that both the complexity of the visual environment and rate of biomechanical effort, and visual information differences between studies, may explain why some studies using direct learning have found turn effects whereas others have not (see, e.g., Herman et al., 1986). The benefit of the new methodology is that the elimination of visual information and locomotive variation provides a pure test of a turning effect, providing confirmatory support that turning does affect memory for distance (see also Jansen-Osmann \& Berendt, 2002).

As well as producing a number-of-turns effect consistent with those shown for routes learned directly, the data from the new methodology afford other similarities with data gathered using more direct naturalistic wayfinding methodologies. Participants encoded distances learned through listening to environmental descriptions without actually traversing any distances and without visual input. Across the experiments, there were reliable correlations between 
actual distance and rewalked distance, indicating that the acquisition of spatial knowledge using this methodology preserves metric properties of real environments (Zwaan \& Radvansky, 1998), and is equivalent to that acquired through direct experience with space (Denis \& Cocude, 1989; Denis \& Zimmer, 1992). Indeed, in all three experiments, remembered segment distances were sensitive to the variation in the actual distances: Short distances were overestimated, whereas longer ones were underestimated (e.g., Byrne, 1979; Decety et al., 1989; Philbeck, Klatzky, Behrmann, Loomis, \& Goodridge, 2001; Radvansky, CarlsonRadvansky, \& Irwin, 1995; Thompson, 1983; Thorndyke \& Hayes-Roth, 1982).

The experiments also show that the new blindfold methodology is successful, thus adding a valuable new technique for investigating cognitive maps acquired indirectly, complementing those currently available. There were two potential concerns with the new methodology, a priori. First, we needed to be sure that the focus of the experiment for participants, as a memory-for-spatial-descriptions task, meant that participants were actually imagining traversing distance rather than merely counting the number of metronome clicks for each segment or route. Given that participants had varying step lengths - and, therefore, varying numbers of metronome clicks given for set distancesit was possible to examine whether the number of heard clicks between participants, and rewalked distance, were correlated. The absence of a correlation for any route in any of the experiments indicates that participants did not gauge the traversed distance through counting the number of clicks, but rather were actually imagining traversing distances (consistent with self-reports on debrief).

We were also concerned, a priori, that participants may have felt uncomfortable and disorientated wearing blindfolds and being turned on the spot. This concern turned out to be unwarranted, with no participants choosing to abandon the experiment partway through, although all were aware of their ethical right to do so. On the contrary, participants found the experience quite enjoyable, and certainly did not report any feelings of discomfort. This is in contrast to virtual-reality experiments, which allow the control of visual input but can have a considerable dropout rate as a result of participants experiencing giddiness and disorientation (Biocca, 1992).

The remaining concern with the methodology that emerged during the experiments was the considerable loss of data in the analyses in the earlier experiments, as a function of participants failing to remember landmarks in the correct order. A data exclusion rate of $22 \%$ across the first two experiments presented a potential barrier to the methodology's being adopted more widely as a tool for use by spatial cognition researchers. However, Experiment 3, using alphabetically sequenced landmark names, eliminated this problem almost completely, thus bringing the methodology to the point where it should be easily adaptable to other research labs interested in visual control and learning spatial environments through indirect means.

Using the methodology, we also examined whether performing an action midroute might also be associated with differences in imagined rewalked distance pre- versus postaction, and whether amplitude of turn might also affect imagined rewalked distance. Amplitude of turn in Experiment 2 was manipulated by participants changing direction by turning either $90^{\circ}$ or $270^{\circ}$. This manipulation did not affect imagined rewalked distance, suggesting that degree of action is unimportant in memory for distance. This finding is consistent with the scaling hypothesis, where the act of turning breaks distances up into shorter segments which are combined to produce an estimate of the total pathway length; given that shorter distances are overestimated and longer distances are underestimated, the path with more turns will be necessarily estimated as being longer than the path with fewer turns.

Performing an extended action, or standing for the same length of time at the midpoint without performing an action, both resulted in a greater imagined rewalked distance for the segment immediately before the midpoint versus immediately after the midpoint. One potential explanation for this could be simply a path effect, where imagined rewalked distances as a function of memory get shorter as one proceeds through the path; but this cannot be the case. Critically, when the time spent performing the action was shorter in Experiment 1, no effect of action on distance was found. So the time spent at the location, and/or doing something different, appears to be critical at the midpoint, compared with other locations.

As Montello (1997) has noted, distance traversed and travel time are obviously related; the farther one walks, the longer it takes. In almost all wayfinding studies, distance and time are conflated, and it is therefore difficult to establish whether participants are remembering distance, time, or both. However, the time estimation literature may be a fruitful avenue for understanding the relationship between travel time and distance estimation, and it is notable that past studies examining time estimation have produced a number of effects very similar to effects in the distance estimation literature (see Block \& Zakay, 1997, for a metaanalytic review). First, for retrospective time estimation, duration estimations are usually lower than actual durations. Second, as time duration increases, estimations become increasingly less accurate (i.e., shorter than they should be). Third, estimations for complex stimuli (where more information is present) are greater than estimations for less complex stimuli. Finally, it has been shown that segmentation affects time-duration estimation (Poynter, 1983; Zakay, Tsal, Moses, \& Shahar, 1994). This result directly mirrors the effects of turning in the present study, and the explanation proposed for this effect on time estimation (Poynter, 1983) echoes the explanation provided just a few years earlier by Sadalla, Burroughs, and Staplin (1980) to explain turning effects.

So what are participants actually remembering in the present experiments (and indeed in other experiments in wayfinding): distance, time, or both? Given the physical relationship between distance and time, it is perhaps not surprising that the processes underlying deviations from actual distances and durations seem remarkably consistent. Moreover, time and distance may well be confusable, and indeed this may be the case in the present experiments. Participants, while standing still or performing ac- 
tions at the midpoint prior to delivering the book or parcel, imagined walking farther for the segment immediately preceding the midpoint than immediately afterward. The likely explanation for this is that the time spent imagining walking and the time spent not walking are both attached to the same segment, and are not differentiable in terms of attention (a point we will return to shortly). The time is attached to the segment prior to the delivery of the object, given that the goal serves as an endpoint for that segment. Hence, distance prior to the midpoint is judged as greater than is the distance for the segment immediately after the midpoint. Given that there was no correlation between the number of metronome clicks and rewalked distance, we know that participants were sensitive to the distance traveled rather than just to the time of travel, so we can discount the possibility that participants in the present experiments were only remembering time. However, the confusion of time and distance may be exacerbated by the current methodology, where the lack of visual input does not allow an attentional distinction between moving and not moving. Testing whether this also occurs in wayfinding, where people stop for varying periods of time, would be a means of establishing whether this also occurs when participants do have visual input.

More generally, the similarities between distance and time estimation allow us to consider the possibility that a single model may be found for both domains. Underlying several theoretical accounts in the time and distance estimation literature is the basic notion that attention to features of the world might affect distance and time estimation. In the present experiment, participants heard metronome clicks representing their footsteps during mental walks. It was clear that they had internalized distance and direction, as well as turn information, for use during recall that had enabled them to get from the starting landmark toward the final destination. Because they were not walking any distance, they seemed to have been encoding the action of turning. In the absence of direct visual information, the memorization was triggered by body movement; i.e., the participants' attention would focus on memory for events (actual turning). However, this form of representation is available for limited periods only. Indeed, several studies have shown that kinesthetic memory, among other characteristics (such as sequential organization) fades quickly (Labbs \& Simmons, 1981; Millar, 1994; Thompson, 1983). Thus, it becomes more difficult to keep the mental representation active; and in order to progress further along the route, the attentional process had to be reinitialized. Given that, when walking naturally, the average person's footstep measures about $70 \mathrm{~cm}$, and that there are two forward footsteps $/ \mathrm{sec}$ (i.e., $1.40 \mathrm{~m} / \mathrm{sec}$ ), it will take $10 \mathrm{sec}$ to walk $14 \mathrm{~m}$. In terms of traversed distance, paths containing three turns were remembered longer $(3 \times 14 \mathrm{~m})$ than were paths containing one turn $(1 \times 14 \mathrm{~m})$. It is not surprising, in terms of the attentional process, that people remember only a certain distance or time, given that they can focus the attention only for the first $10 \mathrm{sec}$ during memorization. The fact that participants remembered walking longer distances for paths containing several turns than for paths with fewer turns corresponded to the fact that they were actually moving (turning) more often on paths with several turns. Consequently, the more turns in a path, the more attention shifts were required.

There are many ways, apart from turns, in which attention can be reinitialized. For example, it has been shown that the number of intervening landmarks on a route affects memory for distance (e.g., Thorndyke, 1981). When a route contains more landmarks, that route is remembered as being longer than when the same route contains fewer intervening landmarks. According to attentional shifting, attending to landmarks will reinitialize attention, and therefore make participants more aware of the distance being traversed. In a similar vein, buildings which are more salient (large buildings, buildings of visual interest, etc.) are more likely to grab attention, and hence to make a difference to the distance remembered. Indeed, it has been shown that salience is also important for memory for distance (e.g., Sadalla et al., 1980).

Attentional shifting may be regarded as a necessary component across models of distance estimation and as a means of bringing together various accounts of distance estimation and time estimation. When one walks a path, the extent to which one attends to the environment may affect memory for distance in the same way as attention to time affects memory for time. Time passes more slowly the more one attends to events as that time passes (although clearly contextual variables at recall are also important for time and distance estimation; see Bugmann, Coventry, \& Newstead, 2007). Moreover, the role of attention in memory for distance can help set the agenda for future studies. The attentional shift hypothesis would maintain that the more attention is grabbed during a route, the longer the route will seem. This offers the potential to encompass a range of explanations for distance estimation within a unified framework. For example, the "cognitive effort" hypothesis, and the scaling hypothesis, have been regarded as competing accounts for distance estimation. The former hypothesis maintains that the more effort involved in traversing a distance, the longer a route will seem (e.g., R. Cohen, Baldwin, \& Sherman, 1978; Newcombe \& Liben, 1982), whereas the latter maintains that features of the environment break up routes into smaller units that are separately estimated and added together. Within the perspective of attentional shifting, carrying a heavy load results in attention to more features of the environment as a result of slowed walking speed, and also as effort requires continual reappraisal of task value. Therefore, both the features of the world and task constraints may affect one's attention to the environment and, therefore, one's memory for it.

If attentional shifting offers a means of explaining a range of distance estimation effects, it should be possible to generate a test of the hypothesis using the new methodology. The model goes beyond other models in predicting that any information that grabs attention during travel should affect distance estimation. One way of testing this would be to give participants descriptions of events while imagining walking a set distance. For example, using the new methodology, "Look at the bird overhead" presented over headphones while the metronome is clicking could 
be predicted to attract attention, and therefore might be associated with a greater imagined rewalked distance. Such information is not associated with a salient feature of the environment, and is not associated with a change of direction during traversal of a path, but of course is associated with greater storage of information during the route; so, on its own, this manipulation cannot exclude the possibility that the amount of stored information affects memory for distance (the information storage hypothesis; see Sadalla \& Magel, 1980). However, this manipulation, crossed with a change of task goal manipulation (e.g., to remember the objects, vs. the places, encountered en route), may begin to unpack the role of attention separate from these other hypotheses. We are currently exploring these possibilities.

In summary, the data from the present experiments suggest that acquiring route information about the spatial world by imagining oneself walking around an environment is associated with a number of turns effect consistent with that found while actually traversing distance. Moreover, the new methodology we have developed in the present article affords a means of testing indirect acquisition of spatial knowledge in a way that complements methods currently available in the armory of the spatial cognition researcher. Finally, the present results show that the relationship between time and distance in acquiring spatial information merits much closer attention, as does the role of attention as a possible unifying construct underlying memory for routes acquired both indirectly and directly.

\section{AUTHOR NOTE}

Correspondence concerning this article should be addressed to K. R. Coventry, Cognition and Communication Research Centre, School of Psychology and Sport Sciences, Northumbria University, Newcastle Upon Tyne NE1 8ST, England (e-mail: kenny.coventry@northumbria.ac.uk).

\section{REFERENCES}

AvraAmides, M. N. (2003). Spatial updating of environments described in texts. Cognitive Psychology, 47, 402-431.

avraamides, M., Loomis, J. M., Klatzky, R. L., \& Golledge, R. G. (2004). Functional equivalence of spatial representations derived from vision and language: Evidence from allocentric judgments. Journal of Experimental Psychology: Learning, Memory, \& Cognition, 30, 801-814.

Barsalou, L. W. (1999). Perceptual symbol systems. Behavioral \& Brain Sciences, 22, 577-609.

BiocCA, A. J. (1992). Will simulator sickness slow down the diffusion of virtual environment technology? Presence: Teloperators \& Virtual Environments, 1, 334-343.

Block, R. A., \& ZaKaY, D. (1997). Prospective and retrospective duration judgments: A meta-analytic review. Psychonomic Bulletin \& Review, 4, 184-197.

Bryant, D. J., \& Tversky, B. (1999). Mental representations of spatial relations from diagrams and models. Journal of Experimental Psychology: Learning, Memory, \& Cognition, 25, 137-156.

Bugmann, D., Coventry, K. R., \& Newstead, S. E. (2007). Contextual cues and the retrieval of information from cognitive maps. Memory \& Cognition, 35, 381-392.

BYRne, R. W. (1979). Memory for urban geography. Quarterly Journal of Experimental Psychology, 31, 147-154.

Cohen, R., Baldwin, L. M., \& Sherman, R. C. (1978). Cognitive maps of a naturalistic setting. Child Development, 49, 1216-1218.

Cohen, S., \& Cohen, R. (1982). Distance estimates of children as a function of type of activity in the environment. Child Development, $\mathbf{5 3}, 834-837$.
Decety, J., Jeannerod, M., \& Prablanc, C. (1989). The timing of mentally represented actions. Behavioural Brain Research, 34, 35-42.

Denis, M., \& Cocude, M. (1989). Scanning visual images generated from verbal descriptions. European Journal of Cognitive Psychology, 1, 293-307.

Denis, M., \& Cocude, M. (1997). On the metric properties of visual images generated from verbal descriptions: Evidence for the robustness of the mental scanning effect. European Journal of Cognitive Psychology, 9, 353-379.

Denis, M., \& Zimmer, H. D. (1992). Analog properties of cognitive maps constructed from verbal descriptions. Psychological Research, 54, 286-298.

Downs, R. M., \& STEA, D. (1977). Maps in minds: Reflections on cognitive mapping. New York: Harper \& Row.

GLENBERG, A. M. (1997). What memory is for. Behavioral \& Brain Sciences, 20, 1-55.

GlenberG, A. M., \& KaschaK, M. P. (2002). Grounding language in action. Psychonomic Bulletin \& Review, 9, 558-565.

Golledge, R. G. (1987). Environmental cognition. In D. Stokols \& I. Altman (Eds.), Handbook of environmental psychology (Vol. 1, pp. 131-174). New York: Wiley.

Golledge, R. G. (1999). Wayfinding behavior: Cognitive mapping and other spatial processes. Baltimore: Johns Hopkins University Press.

Herman, J. F., Norton, L. M., \& Klein, C. A. (1986). Children's distance estimates in a large-scale environment: A search for the route angularity effect. Environment \& Behavior, 18, 533-558.

Jansen-Osmann, P., \& Berendt, B. (2002). Investigating distance knowledge using virtual environments. Environment \& Behavior, 34, 178-193.

Kosslyn, S. M., Reiser, B. J., Farah, M. J., \& Fliegel, S. L. (1983). Generating visual images: Units and relations. Journal of Experimental Psychology: General, 112, 278-303.

LabBs, G. L., \& Simmons, R. W. (1981). Motor memory. In D. Holding (Ed.), Human skills. New York: Wiley.

MCNamara, T. P. (1986). Mental representations of spatial relations. Cognitive Psychology, 18, 87-121.

MiLlaR, S. (1994). Understanding and representing space: Theory and evidence from studies with blind and sighted children. Oxford: Oxford University Press, Clarendon Press.

Montello, D. (1997). The perception and cognition of environmental distance: Direct source of information. In S. C. Hirtle \& A. U. Frank (Eds.), Spatial information theory: A theoretic basis for GIS (Proceedings of Cosit '97, pp. 297-312). Berlin: Springer.

Newcombe, N., \& Liben, L. S. (1982). Barrier effects in the cognitive maps of children and adults. Journal of Experimental Child Psychology, 34, 46-58.

Philbeck, J. W., Klatzky, R. L., Behrmann, M., Loomis, J. M., \& Goodridge, J. (2001). Active control of locomotion facilitates nonvisual navigation. Journal of Experimental Psychology: Human Perception \& Performance, 27, 141-153.

Poynter, W. D. (1983). Duration judgment and the segmentation of experience. Memory \& Cognition, 11, 77-82.

RadVAnsky, G. A., CARlson-Radvansky, L. A., \& Irwin, D. E. (1995). Uncertainty in estimating distances from memory. Memory \& Cognition, 23, 596-606.

Richardson, A. R., Montello, D. R., \& Hegarty, M. (1999). Spatial knowledge acquisition from maps and from navigation in real and virtual environments. Memory \& Cognition, 27, 741-750.

RIESER, J. J. (1989). Access to knowledge of spatial structure at novel points of observation. Journal of Experimental Psychology: Learning, Memory, \& Cognition, 15, 1157-1165.

Rieser, J. J., Pick, H. L., Ashmead, D. H., \& Garing, A. E. (1995). Calibration of human locomotion and models of perceptual-motor organization. Journal of Experimental Psychology: Human Perception \& Performance, 21, 480-497.

RINCK, M., \& DENIS, M. (2004). The metrics of spatial distance traversed during mental imagery. Journal of Experimental Psychology: Learning, Memory, \& Cognition, 30, 1211-1218.

Sadalla, E. K., Burroughs, W. J., \& Staplin, L. J. (1980). Reference points in spatial cognition. Journal of Experimental Psychology: Human Learning \& Memory, 6, 516-528. 
SAdalla, E. K., \& Magel, S. G. (1980). The perception of traversed distance. Environment \& Behavior, 12, 65-79.

TAYLOR, H. A., \& NAYLOR, S. J. (2002). Goal-directed effects on processing a spatial environment: Indications from memory and language. In K. R. Coventry \& P. Olivier (Eds.), Spatial language: Computational and cognitive perspectives (pp. 233-253). Dordrecht: Kluwer.

TAYlor, H. A., \& TVERSKY, B. (1992). Spatial mental models derived from survey and route descriptions. Journal of Memory \& Language, 31, 261-292.

Thompson, J. A. (1983). Is continuous visual monitoring necessary in visually guided locomotion? Journal of Experimental Psychology: Human Perception \& Performance, 9, 427-443.

Thorndyke, P. W. (1981). Distance estimation from cognitive maps. Cognitive Psychology, 13, 526-550.

Thorndyke, P. W., \& Hayes-Roth, B. (1982). Differences in spatial knowledge acquired from maps and navigation. Cognitive Psychology, 14, 560-589.

Tolman, E. C. (1948). Cognitive maps in rats and men. Psychological Review, 55, 189-208.

ZAKay, D., Tsal, Y., Moses, M., \& Shahar, I. (1994). The role of seg- mentation in prospective and retrospective time estimation processes. Memory \& Cognition, 22, 344-351.

ZwAAN, R. A. (2004). The immersed experiencer: Toward an embodied theory of language comprehension. In B. H. Ross (Ed.), The psychology of learning and motivation (Vol. 44, pp. 35-62). San Diego: Academic Press.

ZWAAN, R. A., \& Radvansky, G. A. (1998). Situation models in language comprehension and memory. Psychological Bulletin, 123, 162-185.

\section{NOTE}

1. We ran a first full experiment with 29 undergraduate students ( 9 males and 20 females) using the same method and design as used in Experiment 1, but in this experiment participants heard descriptions only once prior to rewalking routes. On examination of the results, data from 13 participants were excluded, because they did not reproduce the landmarks in the correct order; accordingly, data from only 16 participants (55\%, comprising 5 males and 11 females) were used in the analysis. The results were analyzed the same way as in Experiment 1, and the results mirrored those found in Experiment 1.

\section{APPENDIX A}

Route A Used in Experiment 1

You are in a place called Charlestown, a typical English town. Your starting place is Victoria Park. I am going to take you on a walk from Victoria Park to St John's Basilica. It is quite a nice walk with lots of things to look at on the way.

You are now standing at the gate of a place called Victoria Park. Victoria Park is renowned for its formal and shrub gardens. They are of interest and beauty in all seasons. During summer, Victoria Park hosts a Folk Music Festival. I am going to get you to walk away from Victoria Park along a route called Abbey Road. Start walking now. Stop. Now you turn onto a road called Mount Street. Start walking now. Stop.

You are now in front of a place called the Museum. Look carefully at the Museum's front windows, and you will see they contain fragments of figures of angels holding shields, some of which bear the arms of Henry VI. I am going to get you to walk away from the Museum along a road called Maple Street. Start walking now. Stop. Now you turn onto a road called Fore Street. Start walking now. Stop.

You are now at the entrance of a place called the Central Library. Built of silvery-grey stone, the front of the building has columns and triple arches with elaborate decoration at the tops. Inside the Library, there is an intricately carved oak staircase.

You are standing directly in front of the book return box.

Now I let you post the book in the return box.

You can actually feel the return box in front of you.

So feel the box and post the book.

OK. Now I am going to get you to walk away from the Central Library along a road called Brunel Road. Start walking now. Stop. Now you turn onto a road called Union Road. Start walking now. Stop.

You are now at the entrance of a place called Blewcoat School. Blewcoat School is a picturesque building, which served as a grammar school. It is half-timbered and thatched. The large shrub garden is particularly colourful in spring and early summer. I am going to get you to walk away from Blewcoat School along a road called Fleet Street. Start walking now. Stop. Now you turn onto a road called Bank Street. Start walking now. Stop. Now you turn onto a road called Moorland Road. Start walking now. Stop. Now you turn onto a road called Scott Road. Start walking now. Stop. Now you turn onto a road called Alma Road. Start walking now. Stop.

You are now at your final destination, which is St John's Basilica. The beautiful stained glass window depicts events in the life of the Blessed Virgin Mary. The tower may be visited by climbing the spiral staircase of 176 steps. 


\section{APPENDIX B}

Route A (1-3-3-1) Used in Experiment 2

You are in a place called Charlestown. Your starting place is the Merchant House. I am going to take you on a walk from the Merchant House to St John's Church.

I am going to start you at a place called Merchant House. It is a medieval house well preserved to this very day. The house has a very ornamental bay window. There is a beautiful shrubbery at the entrance. In front of the entrance, there is a decorative stone gatepost.

I am going to get you to walk away from the Merchant House along a road called Silver Street. Start walking now. Stop. Now you turn onto Beacon Street. Start walking now. Stop.

You are now in front of a place called the Museum. It is one of the most interesting museums in town. The museum has an antique-style wooden door. There is a fossilized plaque at the entrance. In front of the entrance there is a sculpture on the ground.

Leaving the Museum behind, you continue walking straight ahead along Beacon Street. Start walking. Stop. You turn now onto South Street. Start walking. Stop. You turn now onto Maple Street. Start walking. Stop. You turn now onto Hill Street. Start walking. Stop.

You are now in front of a place called the Library. It is very popular among people living in Charlestown. The library has a marble staircase at the front. There is a stone table carved with flowers at the entrance. In front of the entrance, there is a sundial.

OK. You are standing in front of the book return box.

Now you bend over to put down the umbrella on the floor.

OK. Now you take the book out of the bag.

Stretch out your arm to feel the return box in front of you.

Now you post the book into the return box.

OK. Now you bend over to pick up the umbrella.

$\mathrm{OK}$.

You are on Hill Street again. Now you continue walking straight ahead leaving the library behind you. Start walking now. Stop. Now you turn onto Summer Street. Start walking. Stop. You turn now onto Park Street. Start walking. Stop. You turn onto Ford Street. Start walking. Stop.

Now you are in front of a place called the Concert Hall. It is the home of the Charlestown Symphony Orchestra. The concert hall has a golden dome-shaped roof. There is a water feature at the entrance. In front of the entrance there is a beautiful cast-iron gate.

Leaving the concert hall behind, you continue walking along Ford Street. Start walking. Stop. You turn onto Cedar Street. Start walking. Stop.

Now you are in front of a place called St John's Church which is your final destination. Its Gothic architecture stands out against its surroundings. The Church has an imposing tower. There is a life-size figure of St John at the entrance. In front of the entrance, there is an intricately carved holy cross. 


\section{APPENDIX C}

\section{Route 1-3-3-1 Used in Experiment 3}

You are in a place called Charlestown, a typical English town. Your starting place is the Abbott's House. I am going to take you on a walk from the Abbott's House to Emmanuel Church. It is quite a nice walk with lots to things to look at on the way.

You are currently standing in front of the Abbott's House. The Abbott's house is a medieval house well preserved to this very day. The bay window is very ornamental. Notice the marble statue of the house's owner at the entrance. In front of the entrance, there is a large pot of colorful shrubs. I am going to get you to walk away from the Abbott's House along a road called Admiral Street. Start walking now. Stop. Now you turn onto Albany Street. Start walking now. Stop.

You are now in front of a place called Belgrave Museum. Belgrave Museum is one of the most interesting museums in the country. The wooden door is intricately carved. Notice the marble stone relief at the entrance. In front of the entrance there is a modern statue lying on the ground. I am going to get you to walk away from Belgrave Museum along Beacon Street. Start walking. Stop. Now you turn onto Bellevue Street. Start walking. Stop. Now you turn onto Boston Street. Start walking. Stop. Now you turn onto Budeaux Street. Start walking. Stop.

You are currently standing in front of a place called Cooper Library. Cooper Library is very popular among people in Charlestown. The large granite lion statue sits at the entrance. Notice the intricately carved iron gate at the entrance. In front of the entrance, there is a cast iron bench.

OK. Now you walk into Cooper Library towards the counter. Start walking (10 steps). Stop.

(1) You wait a moment here at the Library's counter (30 sec - control condition)

(2) Now you bend over to put down the umbrella on the floor. Now you take the book out of the bag. OK. You are standing in front of the book return box. Stretch out your arm to feel the return box in front of you. Now you post the book into the return box. OK. Now you bend over to pick up the umbrella (action/experimental condition)

OK. Now you are going to walk out of the Library. Start walking (10 steps). Stop.

Now you are on Cambridge Street. You walk along Cambridge Street leaving Cooper Library behind you. Start walking now. Stop. Now you turn onto Cedar Street. Start walking. Stop. You turn now onto Clarence Street. Start walking. Stop. You turn onto Columbia Street. Start walking. Stop.

You are currently standing in front of a place called the Derby Hall. Derby Hall is the home of the Charlestown Symphony Orchestra. The big stained-glass door is multicolored and very decorative. Notice the beautiful water fountain at the entrance. In front of the entrance, there is a marble sundial. OK. Now I am going to get you to walk away from Derby Hall along Dickens Street. Start walking. Stop. Now you turn onto Dover Street. Start walking. Stop.

You are currently standing in front of a place called Emmanuel Church which is your final destination. Because of its Gothic architecture, St Emmanuel Church stands out against its surroundings. The large rose window is magnificent. Notice the marble statue of St Emmanuel at the entrance. In front of the entrance stands a tall granite cross.

(Manuscript received January 31, 2005; revision accepted for publication October 26, 2007.) 